\section{Sleep latencies in human subjects: Age, prior wakefulness, and reliability}

H. W. AGNEW, JR., and WILSE B. WEBB

University of Florida, Gainesville, Fla. 32601

The latencies of sleep onset defined by EEG criteria were examined for seven age groups ranging from 21-31 months to 60-69 years. There was a decline in mean latencies with age except for the 60- to 69-year-old group. Forty percent of the latencies were less than $5 \mathrm{~min}$ in the 16-to 69-year age range. Latencies were positively related to pricr wakefulness. Night-to-night latencies showed a low inter-S reliability.

Latency of the human sleep response has received scant attention. Questionnaire (McGhie \& Russell, 1962) and sleep log (Tune, 1969) studies have considered this variable, but an accurate subjective report of sleep latency is difficult to obtain. Measurement of sleep latency by electroencephalographic (EEG) technique is objective and studies are appearing of particular populations such as the aged in association with various experimental conditions; yet, little normative information is available.

This report examines the effect of age and length of prior wakefulness on EEG sleep latency. These data were drawn from studies which described normative characteristics of sleep across a wide age range (Williams, Agnew, \& Webb, 1964, 1966; Agnew, Webb, \& Williams, 1967; Kohler, Coddington, \& Agnew, 1968; Ross, Agnew, Williams, \& Webb, 1968). We have used data from experimental studies to determine the effect of variations in prior wakefulness (Webb \& Agnew, 1965; Webb, Agnew, \& Williams, 1971; Webb \& Agnew, 1971).

\section{Table 1}

Mean and Median Latency to First Stage 1 for Seven Age Groups of $\mathrm{Ss}$ by Night of Sleep

\begin{tabular}{|c|c|c|c|c|c|c|c|c|}
\hline \multirow[b]{3}{*}{ Age Group } & \multicolumn{6}{|c|}{ Night } & \multirow{2}{*}{\multicolumn{2}{|c|}{$\begin{array}{l}\text { Across } \\
\text { Nights }\end{array}$}} \\
\hline & \multicolumn{2}{|c|}{2} & \multicolumn{2}{|c|}{3} & \multicolumn{2}{|c|}{4} & & \\
\hline & Mean & Median & Mean & Median & Mean & Median & Mean & Median \\
\hline $\begin{array}{l}21-31 \text { Months } \\
8 F \text { and } 7 M\end{array}$ & 28 & 28 & 19 & 14 & 17 & 14 & 21 & 20 \\
\hline $\begin{array}{l}8-11 \text { Years } \\
18 \mathrm{M}\end{array}$ & 18 & 10 & 14 & 10 & 15 & 14 & 16 & 12 \\
\hline $\begin{array}{l}16-19 \text { Years } \\
1 \mathrm{~F} \text { and } 24 \mathrm{M}\end{array}$ & 10 & 5 & 11 & 5 & 9 & 5 & 10 & 5 \\
\hline $\begin{array}{l}20-29 \text { Years } \\
14 F \text { and } 15 \mathrm{M}\end{array}$ & 12 & 8 & 12 & 7 & 13 & 10 & 12 & 8 \\
\hline $\begin{array}{l}30-39 \text { Years } \\
1 F \text { and } 14 \mathrm{M}\end{array}$ & 9 & 6 & 11 & 7 & 6 & 4 & 9 & 5 \\
\hline $\begin{array}{l}50-59 \text { Years } \\
1 \mathrm{~F} \text { and } 15 \mathrm{M}\end{array}$ & 8 & 6 & 6 & 5 & 5 & 4 & 6 & 5 \\
\hline $\begin{array}{l}60-69 \text { Years } \\
4 \mathrm{~F} \text { and } 11 \mathrm{M}\end{array}$ & 16 & 12 & 15 & 11 & 15 & 12 & 15 & 12 \\
\hline $\begin{array}{l}\text { Mean } \\
29 \mathrm{~F} \text { and } 104 \mathrm{M}\end{array}$ & 14 & & 12 & & 11 & & 12 & \\
\hline
\end{tabular}

contained less than $30 \mathrm{sec}$ of $8.12 \mathrm{H}_{\mathrm{z}}$ occipital activity. Since all Ss were alpha dominant, the onset of Stage 1 was marked most often by the disappearance of alpha, followed by the appearance of theta waves. A recent reliability check revealed that two scorers can agree on the onset of Stage 1 with $99 \%$ agreement.

\section{RESULTS}

The distributions of sleep latencies obtained from seven normative studies are given in Fig. 1. In the raw data, three groups (21-31 months, $30-39$ years, and 60-69 years) were represented by 45 nights of sleep. The

Table 1 gives the age, sex, and number of $\mathrm{Ss}$ in each normative study. These Ss were selected on the basis of having a waking, resting alpha amplitude of 40 microV (peak to peak). Each $S$ was studied for 4 consecutive nights, and the first night was discarded from data analysis due to the first-night effect (Agnew, Webb, $\&$ Williams, 1966). The infant group was put to bed at 8 p.m. These Ss were quite upset by the electrode application procedures, and their mothers were permitted to remain in the room until they fell asleep. The preadolescents retired at 9 p.m., and the remainder of the groups at 11 p.m. The number of $S s$ in the experimental studies varied between 5 and 12 and were between 18 and 25 years old.

The EEG montages varied from study to study, but each montage contained at least a $F_{1}-F_{7}$ and an $\mathrm{O}_{3}-\mathrm{O}_{2} \mathrm{P}_{2}$ derivation. A typical montage and techniques are described by Webb \& Agnew (1969).

The EEG records were scored in $1-\mathrm{min}$ epochs for the onset of Stage 1 , according to the following criteria: An epoch was scored as Stage 1 when it
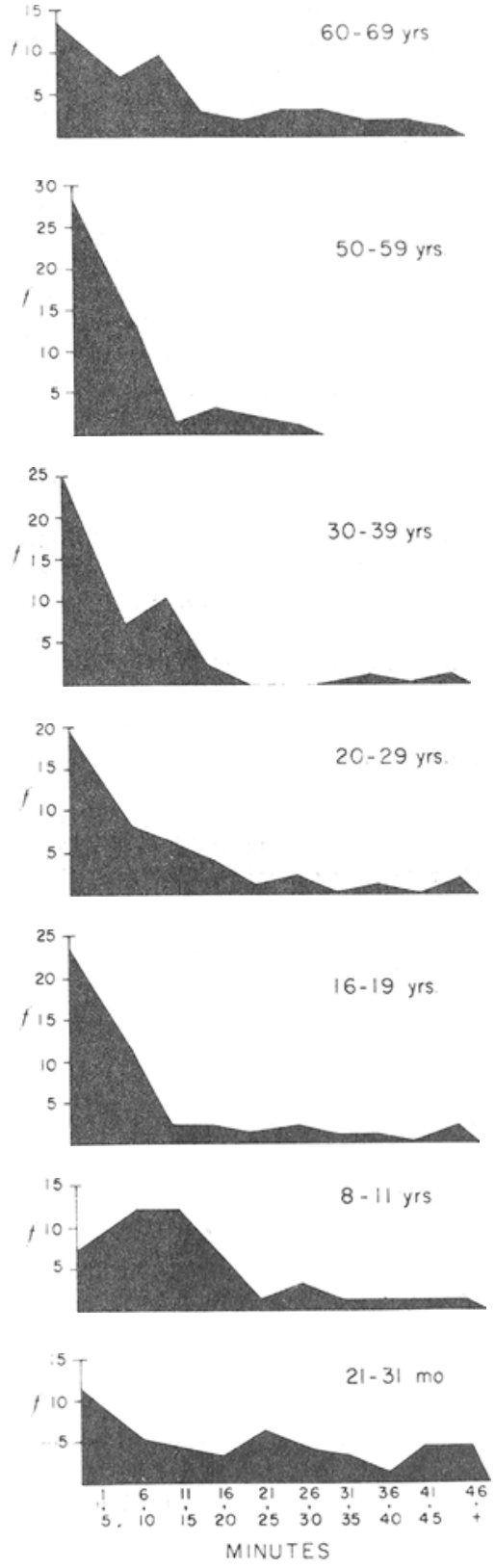

Fig. 1. Frequency distributions of EEG sleep latencies for seven age groups. 
remaining distributions were proportionately decreased to $N=45$ to permit visual assessment of all the data on the same baseline.

Each of these distributions is skewed to the right. The infant group shows the least amount of skew and presents an almost rectangular distribution (see methods section). Ss aged 16-59 years distributed over half of their sleep latencies to 1 to $5 \mathrm{~min}$. Only $7 \%$ of these Ss' responses were greater than $30 \mathrm{~min}$. Across all groups, $40 \%$ of the latencies were $5 \mathrm{~min}$ or less and $60 \%$ were $10 \mathrm{~min}$ or less. The preadolescent group showed relatively longer latencies, with $15 \%$ of this group's responses being $5 \mathrm{~min}$ or less and $40 \%, 10 \mathrm{~min}$ or less.

The mean and median sleep latency is given in Table 1 by group and night of sleep. There is a general tendency for sleep latency to decrease with age. The elderly group shows an increase in latency contrary to this trend. An analysis of variance was computed on the latency scores for each group, using nights as a treatment. Only the infant group showed a significant night-to-night difference in mean sleep latency. The $F$ in this case reached $\mathrm{p}<.05$ for the decreasing latencies displayed by this group. This probably reflected more of an increase in the skills of the $E$ than a real change in sleep latencies. The means at the bottom of this table of 14,12 , and $11 \mathrm{~min}$ point to the relative ease with which Ss in these samples fell asleep.

An analysis of variance was used to test the night-to-night reliability of sleep latencies by computing the intraclass correlations. The highest correlation obtained for any $\mathrm{S}$ group was 0.30 . Since there was very little variation in the mean night-to-night latency for a group, it was expected that the correlation coefficient would



Fig. 2. Chart shows the relationship between hours of prior wakefulness and EEG sleep latency.

be much higher, indicating a high reliability of this measure for a $S$. An examination of these statistics revealed, however, a relatively high amount of variance due to the Ss by Nights interactions. Recalling the earlier data on the distribution of sleep latencies, $60 \%$ of these were within a narrow band of between 1 and $10 \mathrm{~min}$. On the one hand, then, there is a lack of consistent individual differences in these data. On the other hand, the relatively large interaction of $\mathrm{Ss}$ and nights indicates that on some nights these $\mathrm{Ss}$ obtained relatively short latencies and on other nights these latencies were relatively large.

During several experiments, Ss retired at 11 p.m. but were kept awake for varying periods prior to this time. The sleep latency data presented in Fig. 2 were taken from these experiments. When Ss were on a schedule which placed only $4 \mathrm{~h}$ of wakefulness before their habitual bedtime, sleep latency was three times greater than normal. On the other hand, Ss deprived for $65 \mathrm{~h}$ showed an average latency of $1 \mathrm{~min}$.

\section{DISCUSSION}

We would first recognize that our data do not reflect the full population of sleep latencies. Our Ss were selected from the total population. They were paid Ss, screened for an absence of physiological and psychological pathology, and had regular sleep habits as well as an alpha dominance. They were required to sleep in our laboratory under conditions of observation and asked to refrain from drugs or highly variant behavior during the period of measurement. We believe, however, that our Ss do reflect the fundamental characteristics of EEG sleep onset.

The negative relationship between sleep latency and age up to 60 years was a surprising one. Agnew, Webb, \& Williams (1967) noted a decrease in Stage 4 sleep and an increase in awakenings and Stage 1 with increasing age. The present finding of a decrease in sleep latency with increasing age opens up a number of speculative avenues.

We were also surprised by the large proportion of short latency responses; in the age range from 16 to $59,40 \%$ were less than $5 \mathrm{~min}$. Although we recognize that our population consisted of healthy individuals, they were also sleeping in very unusual environments.

The most provocative finding was a low night-to-night reliability of the latencies. With little of the variance attributable to consistent individual difference and the distribution of the latencies sharply skewed toward short latencies, the data suggest the occasional presence of variables which are imposed on sleep onset times independently of the individual's psychobiological constitution.

\section{REFERENCES}

AGNEW, H. W., JR., WEBB, W. B., \& WILLIAMS, R. L. The first night effect: An EEG study of sleep. Psychophysiology, 1966, 2. 263-266.

AGNEW, H. W., JR., WEBB, W. B., \& WILLIAMS, R. L. Sleep patterns in late middle age males: An EEG study. Electroencephalography \& Clinical Neurophysiology, 1967, 23, 168-171.

KOHLER, W. C.. CODDINGTON, R. D., \& AGNEW, H. W., JR. Sleep pattems in 2-year-old children. Journal of Pediatrics. $1968,72,228-233$.

McGHIE, A., \& RUSSELL, S. M. The subjective assessment of normal sleep patterns. Journal of Mental Science. $1962,108,642-654$.

ROSS, J. J., AGNEW, H. W.. JR., WILLIAMS. R. L.. \& WEBB, W. B. Sleep patterns in pre-adolescent children: An EEG-EOG study. Journal of Pediatrics. $1968,42,324-335$.

TUNE, G. S. Sleep and wakefulness in 509 normal human adults. British Jourmal of Medical Psychology, 1969, 42, 75-79.

WEBB,W. B. \& AGNEW, H. W.. JR. Sleep: Effects of a restricted regime. Science, $1965,150,1745-1747$.

WEBB, W. B., \& AGNEW, H. W., JR. Measurement and characteristics of nocturnal sleep. In L.H. Abt and B.F. Riess (Eds.), Progress in clinical psychology. Vol. VIII. New York: Grune \& Stratton, 1969

WEBB, W. B., \& AGNEW, H. W., JR. Effects on sleep of a split period regime. Nature, 1971 , in press.

WEBB, W. B., AGNEW, H. W., JR. \& WILLIAMS, R. L. Effect on sleep of a sleep period time displacement. Aerospace Medicine, 1971, 42, 152-155.

WILLIAMS, R. L., AGNEW, H. W., JR., \& WEBB, W. B. Sleep patterns in young aduits: An EEG study. Electroencephalography \& Clinical Neurophysiology, 1964, 17, 376-381.

WILLIAMS, R. L.. AGNEW, H. W., JR., \& WEBB, W. B. Sleep patterns in the young adult female: An EEG study. Electroencephalography \& Clinical Neurophysiology, 1966, 20,264-266. 